\title{
Impacts Of Ramadan On European Islamic Finance Stock Volatility Based On EGARCH-M Model And Empirical Analysis Of ElIB Stock
}

\author{
Luyao Zhu \\ No.27, Fuxue Street, Changping District, Beijing, China \\ luyao.z@hotmail.com
}

Keywords: Islamic finance stock, ramadan EGARCH-M model, volatility

\begin{abstract}
The thesis firstly introduces the features of Ramadan and Islamic Finance and GARCH model. Then it analyzes the EIIB stock, the representative of Islamic Finance stock via EGARCH-M model, which is applied to data fitting and forecasting, and illustrates the economics meaning of the model. Finally, it comes to a conclusion that Ramadan has a positive influence on the volatility of EIIB stock as well as a negative effect on the returns of it and put forward suggestions on research and practice.
\end{abstract}

\section{Introduction}

After the 2001 "9.11" incident, the Islamic finance increase rapidly. Today, there are more than 300 financial institutions and more than 300 trust "in line with Sharia", which is over 75 Islamic and non-Islamic countries. Britain is the first Western countries to issue sovereign sukuk. Meanwhile, the European Islamic Investment Bank (EIIB) as the first in the UK "in line with Shariah investment" owned bank, has representative and unique significance in the Islamic finance industry in Europe. Thus we want to start from the stock price volatility EIIB, to explore the impact of Ramadan to the European Islamic finance-related stock price volatility.

\section{Reference Review}

Efficient market theory holds that it is impossible to achieve using the available information on market trends forecast. But numerous studies show that the volatility of returns to some extent can be predictable, volatility forecasts for investors can determine market risk situation, thus it is important to have effectively asset pricing, develop trading strategies, construct portfolio and control risk.

In recent years, people are keen to use the GARCH model to study the stock price, swings and even index futures stock. But also reflects its effectiveness. Be the first to volatility modeling and provide a framework model is ARCH model Engle (1982) raised. Bollerslev (1986) presents a useful extended form, called generalized ARCH model (GARCH). GARCH Models have a reduced number of parameters, the weak condition to achieve positive definite advantage. Akgiray relatively use GARCH model and ARCH model to predict the volatility of US stock early. Brooks and Persand use VaR (value at risk) model to study the asymmetry index returns of bad news and good news reactions. Nelson (1991) suggested EGARCH model, using the assumptions GED distribution and so on.

Subsequent empirical study observed yields residuals may also have asymmetric effects on yields, also known as leverage. When the market was negatively affected, conditional variance yields expanded, resulting in more volatile stock prices and yields; on the contrary, when the stock price rises, volatility is reduced. Shares fell causes the Company's stock value drop, assuming constant corporate debt, the company's financial leverage increased, increase the risk of holding the stock. Therefore, the negative impact of this effect on the conditional variance is also known as leverage (http://baike.baidu.com/view/939517.htm?fr=aladdin). Glosten, Jagannathan and Runkel (1993) analyzed and compared various GARCH-M model, pointing out the different settings will 
cause that the conditional variance models have different positive or negative impact on profitability.

Volatility on domestic and foreign research papers are more, using GARCH model is greater, but most are applied to the Shanghai and Shenzhen 300 or SP500 research; at the same time, at home and abroad, although covered on Islamic finance, but more are ending simple analysis of theoretical exploration, replicability analogies and empirical data, and did not focus on Islamic finance-related stock price volatility. Therefore, this article will research methods GARCH Models superiority and unique perspective of Islamic finance-related stock price volatility contact, exploring the impact on Ramadan to the share price volatility.

\section{Ramadan, Islamic Finance Overview}

Ramadan. Ramadan is one of Islam's five major religions of worship course. In Ramadan, the Arab countries are generally adjust working hours, most of the UAE's working hours are 8:00 am to 2:00 pm, Saudi provisions 10:00 am beginning to work. Lower operational efficiency of government agencies, but also a corresponding reduction in the activities of businessmen, Arab business activities carried out in the evenings. People during Ramadan due to the low efficiency of the Gulf Arab states during the day, often cannot find people, so for business visits and business negotiations, they usually try to avoid Ramadan to visit.

Islamic Finance. The main principles of Islamic Finance: (1) prohibiting the collection and payment of interest. (2) prohibiting the trading of uncertainty. (3) profit and loss assessment. (4) prohibiting speculation. (5) in a lease way to have a profit. (6) "Hosni raha system" (meaning "mark-up"). (7) fee system. Because of characteristic of their risk-sharing, speculation-prohibiting, stress spirit of the contract, Islamic finance-related stocks in the stock market has a more stable and considerable appeal. Especially since the US subprime mortgage crisis triggered by the financial crisis spread, causing widespread concerns about the global economic downturn, many investors believe that "Sharia compliance of financial operations" is more reliable than the traditional financial sector.

\section{EGARCH-M model building}

Data Acquisition. This paper selected EIIB closing price on May 17, 2006 to October 31, 2014, a total of 2197 observations. We establish the sequence $\{p\}$, and then build its number of return series $\{r\}$, establish conditional heteroskedasticity models for the sequence $\{r\}$, and to study the volatility of its earnings. [Data from Yahoo finance!] Here, the logarithmic rate of return expressed as:

$$
r=\ln P_{t} / P_{t-1}
$$

Among them, $P_{t}$ is closing price, $P_{t-1}$ is the previous day's closing price. After the unit root test, logarithmic yields sequence $\{r\}$ proves stability.

ARCH Effect Test. Logarithmically with Eviews7.2 sequence $\{r\}$ return autocorrelation and partial autocorrelation analysis to determine its lag order is 1 . Therefore, the establishment of AR (1) model is as follows.

$$
r_{t}=-0.295607 r_{t-1}+a_{t}
$$

Among them, $r_{t}$ is year logarithm returns, $r_{t-1}$ is one-year lag that is the number of the previous year to yield, $a_{t}$ is Residuals. Strict ARCH-LM test, the results shows the existence of a sequence of squared residuals $\left[a_{t}^{2}\right\}$ order autocorrelation, that model error sequence is present autoregressive conditional heteroskedasticity, i.e. ARCH effects. Thus in the applicability of the model, it is suitable for using GARCH Models. 


\section{EGARCH-M Modeling}

Basic Structure Of The Model. Since EIIB stock logarithmic return series $\{r\}$ is not normal, so in trying to establish the GARCH model of the process, the selection of the GED distribution assumptions. Establish EGARCH-M model with Eviews7.2, results are as follows:

$$
\begin{gathered}
r_{t}=-2.73 * 10^{-5}-0.000741 r_{t-1}+0.011449 \sigma_{t}^{2}-0.001388 \mu_{t}+a_{t} \\
\ln \left(\sigma_{t}^{2}\right)=-5.012066+1.052616 \frac{\left|a_{t-1}\right|}{\sigma_{t-1}}-0.093410 \frac{a_{t-1}}{\sigma_{t-1}}+0.170065\left(\sigma_{t-1}^{2}\right)+3.264591 u_{t} \\
r_{t}=\frac{-0.93410}{1.052616}=-0.088740813, a_{t}=\sigma_{t} \varepsilon_{t} \\
u_{t}=\left\{\begin{array}{ccc}
0, & t \text { doesn't } & \text { belong to Ramadan } \\
1, & t \in \text { Ramadan }
\end{array}\right.
\end{gathered}
$$

Among them,

$$
\begin{gathered}
\gamma_{\mathrm{t}}=\frac{-0.093410}{1.052616}=-0.088740813, a_{\mathrm{t}}=\sigma_{\mathrm{t}} \epsilon_{\mathrm{t}} \\
u_{\mathrm{t}}=\left\{\begin{array}{c}
0, t \text { doesn't belong to Ramadan } \\
1, \quad t \in \text { Ramadan }
\end{array}\right.
\end{gathered}
$$

$r_{t}$ is on behalf of the number of shares on the date of return;

$r_{t-1}$ is on behalf of stock from the previous day the logarithmic rate of return;

$a_{t-1}$ represents the number of shares the day before the stock to return residuals;

$\sigma_{t}^{2}$ represents the number of shares on the date of return volatility, the variance;

$u_{t}$ is the author added, "dummy variables";

$\gamma_{t}$ represents the leverage effect of $a_{t-1}$, the result is negative, in line with our requirements in the practical application.

Model Interpretation. The model is actually a combination of EGARCH, GARCH-M, AR model and the "dummy" $u_{t}$. First, the model characteristics have EGARCH model, reflecting leverage on the number of return series. Obviously, the conditional variance equation can be seen, the negative effect of the disturbance caused by the fluctuation contribution to exceed the positive contribution of the disturbance caused by the effect of fluctuation, and the whole idea that economics is consistent confidence. Then, the model has the characteristics of GARCH-M model, so in line with the financial sector depends in part on the yield volatility (i.e. risk) of the theoretical framework. The theoretical framework is consistent with the CAPM. While that the coefficient is positive is a proof of the benefits and risks of a positive correlation between theoretical ideas. In addition, the model has the characteristics of AR model. Model number reflects the day to yield not only by the date of the impact of new information, but also by the number of the previous day on yields. In addition, the "dummy variable" is a variable we set manually when building the model. When the time when the agreement is located in the holy month of Ramadan, X, when time is not located within the month of Ramadan, Y. At the same time, from the model mean equation can be seen, when in the month of Ramadan, the log will yield, the negative impact from the conditional variance equation can be seen, when the time in the month of Ramadan, will yield volatility bring positive impact. That is, when the time is located in Ramadan, the logarithmic stock returns will be reduced, while the volatility of the stock price increases.

Assessment of Model's Fitness. All models have passed the confidence coefficient of $1 \%$ of the $\mathrm{z}$ test, so fitting of the model is very strong. From the prediction model can be seen from Figure 1, the model is well reflected in the volatility and "seasonal" effect on the number of the yield curve, and is bounded fluctuations. In addition, ARCH-LM test for new model residuals shows that the 
new model doesn't have autoregressive conditional heteroskedasticity, which meets the previous statistical assumptions.
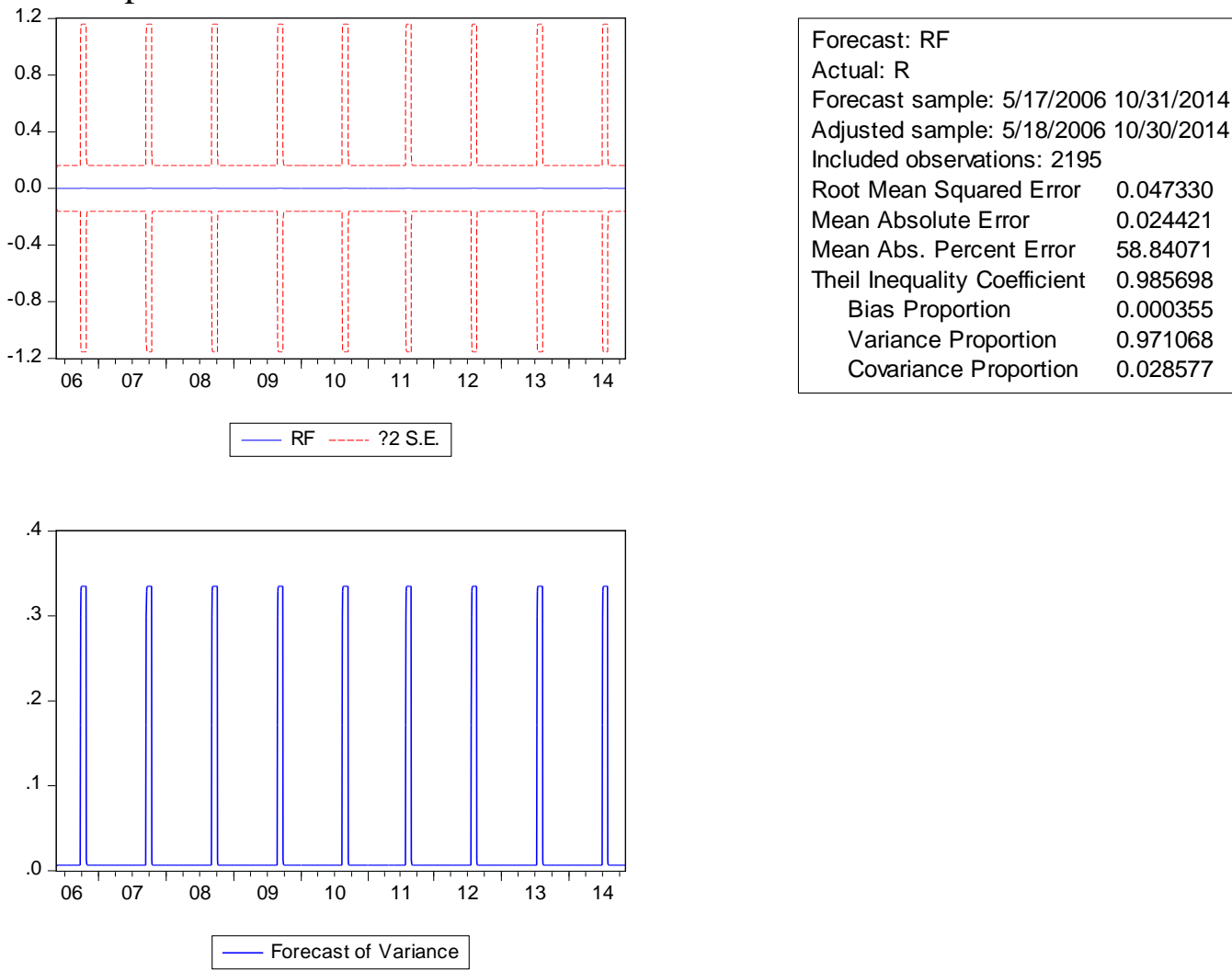

Figure 1 Forecast of the Model

Meaning Of The Model. As can be seen from the model, Ramadan is not only affected the number of stock returns, but also affect the volatility of the stock. And this effect is of practical significance from mathematical logic and meaning from the perspective of economics. According to the author of the analysis, Ramadan will come roughly from shareholders, management and customers have an impact yields and volatility of the bank.

Consider the shareholder level. After verification of the European Islamic Investment Bank shareholder structure, the bank's main shareholder is the Gulf country's financial institutions and individuals, in particular suggest that these people are mainly related to Islamic financial institutions and individuals, and these are the Islamic Gulf countries. Therefore, it is considered a component of shareholders EIIB bank inside a large proportion of Muslims. Since the bank is strict compliance with the Shariah provision, so all transactions, which performs production activities are in line with Islamic transaction, which is that it attracts a large number of Muslims handle the relevant business, the reason to buy its stock. From the foregoing description of the activities of Muslims in Ramadan characteristics shows that the activities of these shareholders in the month of Ramadan will have impact on the bank equities, the usual appearance will decline in trading volume.

From the perspective of management and staff, EIIB has special Shariah directors, and the appointment of managers at all levels is also strictly abided by the teachings of Islam. At the same time, there are more staff members as Muslims. So Ramadan activities will affect the daily work of these groups, which affects the amount of the company's daily business.

From the customer level, the bank's customer is a large proportion of Muslim population. Since its operation operates in line with the teachings of Islam, while other banks financial services cannot meet the needs of Muslims. So, Ramadan activities will affect the business activities of Muslim customers, while also affecting the business volume of the bank.

Because the amount of banking will affect banks thus affecting the intrinsic value and its stock 
price fluctuations, but also affect the sale of operations shareholders fluctuations in stock prices. Thus from an economic point of view to explain the significance of the model is to have relevance.

\section{Conclusions}

Model results shows that Ramadan will have a negative direction influence on EIIB stock logarithm returns, and would have a positive direction influence on volatility of stock price. That is, in the month of Ramadan, the logarithmic yields EIIB significantly reduced, and the stock price volatility is significantly larger. This effect is more intense, causing stock prices have a "seasonal" fluctuations. In addition to a glimpse of the volatility of the stock price of Lent customs activities on this special, we can also see the positive market disturbances and perturbations negative effect on the stock price volatility is different. This is consistent with the "leverage effect" setting.

Stock returns not only by the influence of Lent, while also subject to the yield on the impact and influence of the current volatility. Especially the latter, reflecting the risk and return was a positive correlation, but also meet the theoretical framework of the CAPM. Also can be seen, for Islamic finance-related stock market, it also can accurately reflect the market information.

For the above conclusions, we can have the following recommendations:

First, because Ramadan is one of three major festivals of Islam, with a long and strict customs constraint, thus affecting Ramadan Islamic finance-related shares will be "seasonal" and appears to be stable. In view of this situation, in the study of volatility and the yield of Islamic finance-related shares, we should not ignore this particularity. It is also for the investors who tend to invest in the field of Islamic finance to have brought a more cautious and targeted suggestive.

Secondly, because in the Islamic financial equity markets, risk and return are positively related, and empirical studies have proved more effective in this market. Thus in terms of investment in Islamic financial stocks, we should consider the effectiveness of its own operations and the soundness of the market. If you choose to speculative investment seems to be rather irrational.

Finally, in the direction of investment with the Islamic finance-related stocks, we have to be vigilant Lent brings its "leverage." When the negative market disturbances produce, share price decline, causing the stock decline in value. In the amount of debt the same premise, the company's leverage increases, which makes venture capital becomes higher.

\section{References}

[1] Moin Siddiqi: Islamic Banking , Middle East, November 2008, p.36.

[2] Islamic Finance: Global Trends and Challenges, NBR ANALYSIS, Volume 18, Number 4, March 2008, p.3.

[3] Moin Siddiqi: Islamic Banking , Middle East, November 2008, p.35.

[4]Shuangqing Chen: "Islamic finance industry and its development characteristics" [J], "International data and information", 2009 (06)

[5]Quan jiang, Meng Liu: "HS300 index return volatility and VaR Metrics" [J], "financial economy", 2008 (08): 87-89

[6]Dehua Chen, Jianmin Shi: "China's stock market volatility risk prediction: A Comparative Study on the Shanghai and Shenzhen 300 Index" [J], "productivity studies", 2009 (4): 36-38

[7]Ping-Tsung Wu, Shwu - Jane Shieh: Value - at - Risk analysis for long - term interest rate futures: Fat- tail and long memory in return innovations [J].Journal of Empirical Finance, 2007,14: p.248-259.

[8]Xiao Liu, Yimin Li: "GARCH family model in the stock market: The Shenzhen Component 
Index on volatility " [J], "Technology Economics and Management Research", 2005 (05): 36-38

[9]Liping An , Bo Wang, Xidong Shen : "GARCH family model based on the Shanghai and Shenzhen stock VaR measure" [J], "Mathematical Theory and Applications", 2014 (02): 94-102

[10]Jinwen Zhao: "Simulation of GARCH Models SSE 180 Index on: indirect empirical modeling of the Shanghai 300 Index Analysis" [J], "Finance and Economics Research", 2008 (03): 48-54

[11]Rui Gong, Dongrui Yang: "GARCH Family Model Chinese Stock Market Value at Risk: A Comparative Study and Review VaR risk" [J], "Quantitative and Technical Economics Research", 2005 (07): 68-81

[12] Libing Fang, Bingkun Guo, Yong Zeng : "ability to predict the GARCH model is relatively a semi-parametric method" [J], "Quantitative and Technical Economics Research", 2010 (04): 148-160

[13]Xuhui Ding,Xinyu Gao, Kaikai Yang: "The international gold price volatility and Risk Prevention Research: An Empirical Analysis of the GARCH model" [J], 2014 (07): 72-74 